\title{
chopter Life, Change and Charisma: Memories of UK Psychiatric Hospitals in the Long 1960 s
}

\author{
Thomas Stephenson and Claire Hilton
}

\section{Introduction}

Psychiatric hospitals across the UK were in various states of change during the long 1960s, influenced by legal, medical, ideological, social, psychological, financial and other factors. The Mental Health Act 1959 (MHA) created more liberal admission processes and encouraged community care. The Suicide Act 1961 decriminalised suicide and attempted suicide. New medications were available and multidisciplinary teamwork developed. Societal perspectives shifted concerning individuality, personal autonomy and human rights. In the face of a more educated, less class-deferent society, paternalistic 'doctor-knows-best' attitudes became less acceptable, although clinical styles which infringed on human dignity continued in many National Health Service (NHS) settings. ${ }^{1}$ New organisations, such as the Patients Association, and older ones, such as the National Association for Mental Health (today, Mind), began to campaign for patients' health care rights (see also Chapter 14). Antiquated psychiatric hospitals were expensive to maintain and stimulated government policies to close them. Psychiatric hospital beds in England and Wales, which peaked at 148,000 in 1954, reduced to 136,000 in 1960 and to 94,000 in 1973 (see also Chapters 1 and 31$)^{2}$

Decisions and actions within health care institutions, from central government down, impact on the lives of individual patients, their families, the staff and the wider community. However, too often, experiences of individuals are ignored in historical analyses. Recognising this for mental health care, oral history resources have been developed, such as the Mental Health Testimony Archive, ${ }^{3}$ comprising patients' life stories and health service experiences. Some people wrote memoirs, such as psychiatrists William Sargant and Henry Rollin, ${ }^{4}$ and community projects such as at the former Whittingham Hospital, Preston and Fairfield Hospital, Stotfold, are recording the lives of the people associated with them. To complement existing resources of personal experiences, we convened a witness seminar on psychiatric hospitals in the 1960s. A witness seminar allows invited witnesses to present their memories and to discuss them with each other and a participating audience. Challenge and comment are akin to open and immediate peer review. Seminars are recorded, transcribed, annotated and made available as a primary historical resource. ${ }^{5}$

Witness seminars are inevitably selective and subjective and include contributors' prejudices and personal agendas. These biases may be less evident in written archives, especially official or clinical documents, but they still exist and all sources need critical analysis. Our witness seminar aimed to be multidisciplinary, drawing on experiences from across the UK. Lifespan, health and competing commitments were factors limiting availability of witnesses. Unfortunately, we had only one patient witness and none from the civil service or black and Asian ethnic groups. 
Table 6.1 Witness seminar participants quoted in this chapter

\begin{tabular}{|c|c|c|c|}
\hline Name & $\begin{array}{l}\text { Initials (used } \\
\text { in text) }\end{array}$ & $\begin{array}{l}\text { Role/context } \\
(1960 \mathrm{~s})\end{array}$ & $\begin{array}{l}\text { Affiliated hospital } \\
\text { (1960s) }\end{array}$ \\
\hline Dora Black & DB & Junior doctor & Napsbury, Hertfordshire \\
\hline Bill Boyd & $\mathrm{BB}$ & $\begin{array}{l}\text { Consultant } \\
\text { psychiatrist and } \\
\text { physician } \\
\text { superintendent }\end{array}$ & Herdmanflat, East Lothian \\
\hline John Bradley & $J B$ & $\begin{array}{l}\text { Consultant } \\
\text { psychiatrist and } \\
\text { medical director }\end{array}$ & Friern, London \\
\hline $\begin{array}{l}\text { Malcolm } \\
\text { Campbell }\end{array}$ & $M C$ & Junior doctor & Friern, London \\
\hline Peter Campbell & $P C$ & Patient & $\begin{array}{l}\text { Addenbrookes, } \\
\text { Cambridge; Royal Dundee } \\
\text { Liff, Angus }\end{array}$ \\
\hline Susanne Curran & SC & $\begin{array}{l}\text { Mental welfare } \\
\text { officer (psychiatric } \\
\text { social worker) }\end{array}$ & $\begin{array}{l}\text { Prestwich and } \\
\text { Rossendale, Lancashire }\end{array}$ \\
\hline John Hall & $J H$ & Clinical psychologist & St Andrew's, Norwich \\
\hline John Jenkins & ر & Student nurse & Parc Gwyllt, Bridgend \\
\hline David Jolley & DJ & Medical student & Severalls, Colchester \\
\hline Jennifer Lowe & $J$ & $\begin{array}{l}\text { Occupational } \\
\text { therapist }\end{array}$ & Littlemore, Oxford \\
\hline Peter Nolan & PN & Student nurse & Tooting Bec, London \\
\hline Geraldine Pratten & GP & $\begin{array}{l}\text { Lived with her family } \\
\text { in a hospital staff } \\
\text { house }\end{array}$ & Crichton Royal, Dumfries \\
\hline $\begin{array}{l}\text { Angela } \\
\text { Rouncefield }\end{array}$ & $A R$ & Junior doctor & $\begin{array}{l}\text { Sefton General; } \\
\text { Birkenhead General; North } \\
\text { Wales, Denbigh }\end{array}$ \\
\hline Peter Tyrer & PT & Junior doctor & $\begin{array}{l}\text { St Thomas' and Maudsley, } \\
\text { London }\end{array}$ \\
\hline Harry Zeitlin & $\mathrm{HZ}$ & Junior doctor & Maudsley, London \\
\hline
\end{tabular}

In this chapter, we present some of the seminar themes, focusing on experiences in the hospitals and some of the clinicians and patients who inspired and influenced change. Discussion jogged memories onto other topics and anecdotes, such as ethics, leadership, gender and professional training, far more than can be explored in this chapter. The transcript, witnesses' biographies and a commentary on some of the more controversial themes are free to download. ${ }^{6}$ In this chapter, references to the seminar are indicated by transcript page numbers and the speaker's initials (Table 6.1). 


\section{Onto the Wards}

In the 1960s, most psychiatric hospitals were suburban or rural. Many were 'total institutions', as Erving Goffman described, places of residence and work where many like-situated individuals, cut off from wider society for an appreciable period of time, led an enclosed and formally administered way of life. ${ }^{7}$ The public were often fearful of the hospitals $(\mathrm{SC}, 20)$ and avoided them. Staff too could find them disconcerting, the 'foreboding experience of a very long, dimly lit corridor' (MC,25) could provoke panic $(\mathrm{JB}, 50)$. MC (25) also remembered the 'overall pervading ... smell, a mixture of incontinence and disinfectant' and others recalled the foul odour of the sedative paraldehyde $(\mathrm{JB}, 27)$, while written sources mentioned smells of vomit, faeces, cats, mothballs, cooking, ozone machines, flowers, talc and freshness. ${ }^{8}$

Psychiatric wards were gender segregated, but some hospitals were 'bringing the genders together for civilised activities' (DJ,12). Nevertheless, PC (16) recalled: 'men and women used to come down to mealtimes at slightly different times and sit at different tables. It was a brave person who made up a mixed table.' Whereas ward staff were usually of the same gender as their patients, doctors generally worked across several wards and were not. Women hospital doctors were few and far between, ${ }^{9}$ and when they worked on the 'male side', there could be practical difficulties: 'no ladies [toilets] in the male units: a male nurse would stand outside the gents while I went in' (AR,47). Male and female wards also had different cultures. Since our nurse and patient witnesses (JJ; PN; PC) were all male, their descriptions might be less applicable to female wards. Male wards were more militaristic and arguably physically harsher than women's wards, which perpetuated different sorts of detrimental practices. ${ }^{10}$

Distressing mental symptoms could preoccupy a new patient:

traumatised by my situation ... extremely anxious. I believed I'd been taken away to die ... I would wander around the ward. My concentration was extremely poor. I tried to watch the television but could make no sense of it. This distressed me greatly.

$(\mathrm{PC}, 16)$

Ward environments might add to distress:

The day room always seemed crowded with constant movement. Although there were few comfortable places to sit, it was where patients smoked, had their meals, met visitors, listened to the radio, watched television, had cups of tea, sat alone or chatted in groups. No matter how often the ashtrays were emptied they were always full.

$(\mathrm{PN}, 26)$

Sometimes there were insufficient chairs. The only escape was to sit in the toilets smoking or just sleeping which often happened, thus blocking the use of some toilets' (PN,69). Some hospitals attempted to improve environments but patients might resist change:

we got lovely comfortable chairs with coffee tables so that the patients could sit in nice little groups. Of course, when I came in the day after it was in action, the patients were all sitting around the wall .... backs to the wall and I said, 'What's happening?' And the nurses said, 'Well, that's what the patients wanted to do' so we just had to go along with it.

$(\mathrm{BB}, 52)$

Communal living arrangements, few personal possessions and the loss of usual social roles and relationships diminished patients' sense of individuality and promoted conformity with ward regimes. ${ }^{11}$ Rigid regimes might ease life for staff but could be unhelpful to patients. PC (16) recalled: 


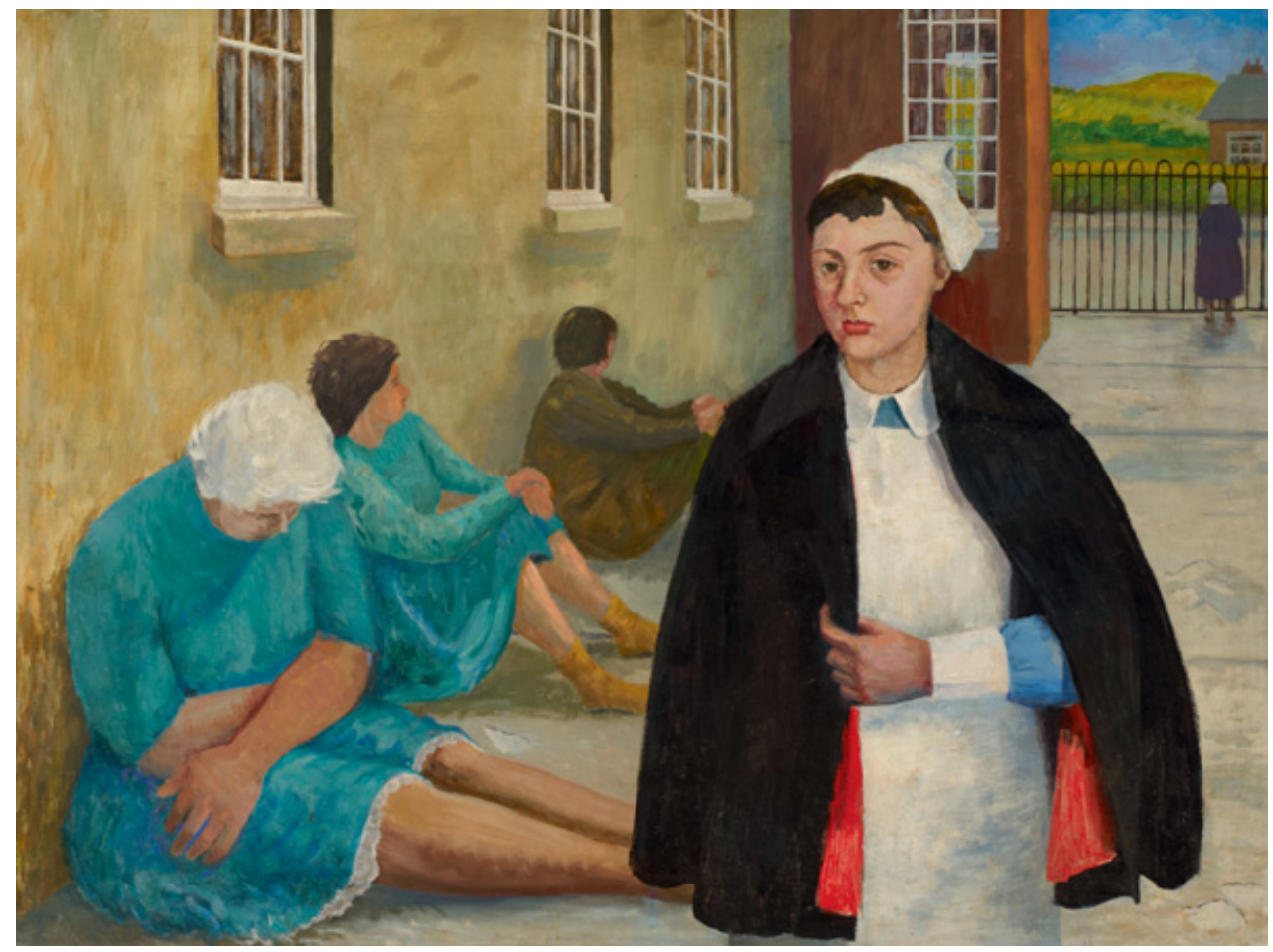

Figure 6.1 Institutionalised indifference: Russell Barton's painting, Potential Murderers? c.1960. ( ) Bethlem Museum of the Mind.

I found it very difficult to sleep. I remember lying in bed waiting for the right time to go and ask for chloral hydrate. Too soon, and I would be sent back to try again. Too late, and I would also be refused.

Some procedures, rules and inadequate facilities were also challenging to staff:

I entered [the ward] briskly to prevent a possible key snatch or an escape attempt. The necessary rituals of saying good morning to the charge nurse and donning a white coat completed, the day started. Getting the patients up, dressed and washed before breakfast were priorities. Only having three wash basins and three toilets [for twenty-six patients] often delayed this process and frequently led to annoyances and confrontations. (PN,26)

Seminar participants spoke of interactions, between staff and patients, among patients and among staff. JJ (36) recalled an encounter with a senior nurse, who, because of his rank, was likely to influence staff attitudes and practices: 'I was given a very large key and taken ... to ward eight. [The nurse] only spoke a few words ... I will never forget ... "The key is the most important thing here and what it represents is your power over the lunatics." The obsolete word 'lunatics' suggested outmoded attitudes towards patients, and 'power over' suggested a coercive culture, unlikely to foster kindness. Some staff showed institutionalised indifference' (Figure 6.1), walking past patients because 'being busy was preferable to being engaged' (PN,28), but there was also kindly interaction: 
Assisting with [personal care] tasks, patients would sometimes confide to nurses such things as, 'It's my birthday today' or 'Today is the tenth anniversary of my leaving the army.' I often found myself captivated by observing the good-natured gentleness with which able bodied patients helped those less able.

$(\mathrm{PN}, 26)$

PN's observation resonated with the 'kind of camaraderie' among patients which PC (17) experienced.

Medical staff as well as nurses could ignore patients' personal dignity. PC (17) described ward rounds:

We stood by our beds with our kit laid out neatly. The consultant and his retinue went from dormitory to dormitory and he interviewed us briefly where we stood and in front of all the other patients. It was nerve wracking, as ward rounds always are, but also lacking any confidentiality.

This style of ward round was unacceptable elsewhere, such as at Crichton Royal Hospital, Dumfries. $^{12}$

Many staff, distressed by practices which they witnessed or experienced, lacked the confidence or know-how to challenge them. Juniors also feared that, in a culture of deference to seniors, antagonising those in authority might jeopardise their future careers. The NHS's first formal complaints guidance in 1966 had little effect and did not shift the defensive culture of NHS leadership. ${ }^{13}$ However, NHS leaders began to acknowledge detrimental psychiatric hospital culture and practices in 1969, after inquiries into scandalously poor standards of psychiatric care. ${ }^{14}$ Those reports echoed our witnesses' memories (JJ,36). The Ely Hospital, Cardiff, inquiry attributed bad practice to defective leadership in an inward-looking institution rather than to inherent malice. $^{15}$

Some senior staff supported their distressed juniors in the event of a death by suicide $(\mathrm{JH}, 28)$ but others did not. PN (27) recalled a recently discharged patient being found dead on Tooting Bec Common. The only acknowledgement from staff was that: 'I was asked to take his case-notes to the medical records office to be filed away.' Yet, for PN, 'His death profoundly affected me. There was no funeral, but I grieved for him.' Speaking about it fifty years later: 'I found myself back on that ward again. There was no emotional support, the term was never mentioned ... the way it was coped with was merely to ignore it' $(\mathrm{PN}, 28)$. DB (40) also remembered a patient she had treated:

a seventeen-year-old epileptic girl ... she asked ... to go out into the grounds and she'd been very stable and I didn't see any reason why I shouldn't give her permission and I did. But there was a railway that ran on the north border of Napsbury Hospital ... And she was found dead on that railway track ... nobody was sure whether she'd deliberately gone and killed herself or whether she'd had an epileptic fit ... it was never really sorted out ... And I always wondered if I should have given her permission to go out ... I've remembered it for ... sixty years.

Historians have tended to see patients as victims and staff as perpetrators, ${ }^{16}$ but the seminar pointed to a complex mix of experiences and emotions for both groups. Some staff had indelible painful memories and ongoing self-questioning about their own roles at the time (PT,30). Memories of unkindness haunted them, spurring them on to improve clinical practice over the course of their careers (JJ,37; PN,54). 


\section{Treatment}

A daily routine, meaningful employment and social and leisure activities were all part of treatment, alongside medication and electroconvulsive therapy (ECT). New professions joined the hospitals, such as occupational therapists (OTs) and clinical psychologists, reflecting the challenges of accurate diagnosis, a broader range of treatments and a greater emphasis on discharging patients into the community. Psychologists, however, focused mainly on assessment $(\mathrm{JH}, 42)$ : 'Full psychometrics please' was often requested for a new inpatient, sometimes with its purpose difficult to ascertain $(\mathrm{PC}, 19)$. JH (43) referred to routine psychometric testing as 'test bashing'.

Employment was considered to benefit self-esteem and well-being, through creativity and 'the involvement, fellowship, the jokes that would come from work' (DJ,16). At Severalls Hospital, 'the most damaged people' would 'turn cement', from which others would 'make slabs and they would sell the slabs in the town' (DJ,12). DJ (12) also pointed out 'what a tragedy at the moment, if you ask what people [with severe mental illness] are doing, there's no work' for them, referring to a report in 2013 which found UK employment rates of around 8 per cent for people with schizophrenia and stated that many more could work and wanted to do so. ${ }^{17}$

'Industrial therapy' (IT) fitted with the ethos of rehabilitation and discharge into the community. It was conceptualised as employing patients under clinical supervision in factory-type work appropriate to their individual needs, including providing psychological and economic satisfaction. If IT managers set up external business contracts, patients could be paid $(\mathrm{JB}, 16)$. For patients engaged in non-IT hospital work, there were several material reward systems: cash; a 'token economy' based on psychological principles; and 'rewards in kind' which some senior psychiatrists criticised as 'out of keeping with modern views'. ${ }^{18}$ Overcrowded wards lacking individual lockers for storing personal possessions put valued items at risk of theft and deterred hospitals from providing cash or tokens. ${ }^{19}$

Newly qualified OT JL (35) was deployed to a long-stay ward: 'I found it hard to feel that there was any good that I could do.' Bingo as an activity 'for heavily sedated patients, was very badly decided upon':

Patients sat around tables with their bingo cards in front of them and one of us shouted out the numbers. We would then run around the tables moving the numbers for them and when a card was full, we would pick up a hand and shout, 'Come on Jan! Come on Alice!' or whoever it was, 'Shout Bingo! You've won!' It was impossible and exhausting.

JL (35) described her OT role as a 'cosmetic addition'. JH (42), another new hospital professional, commented: 'I was the first junior trained psychologist they had ever had, and to be honest I am not sure they knew what to do with me!' Hospital leaders developing multidisciplinary teams, with one eye on financial expenditure and uncertainty about what newcomers were able to do, could create impossible workloads. ${ }^{20}$

PC (19-20) described being treated with ECT, noting that it is given differently today:

another patient [said] to me, 'Oh, you need ECT. You'll be given ECT. They'll do this and that to you in ECT.' And because ECT sounds awful, you start worrying about being given ECT ... I remember being in a Nightingale ward and being lined up on a bed and the ECT machine worked its way down to you ... You were just in the ward and the ECT machine came down to you and you could hear it getting nearer and nearer to you. 
For many seminar participants, this disturbing description was a lasting memory of the day. Medications, such as chlorpromazine, reserpine, imipramine and monoamine oxidase inhibitors which could modify the symptoms and course of 'functional' psychiatric disorders such as schizophrenia, were newly available. ${ }^{21} \mathrm{DB}(40)$ recalled their effect on her patients:

In $1957 \ldots$ my senior registrar ... put everybody on reserpine ... it was like Oliver Sacks talked about with levodopa ... Many of them, just started walking and talking and being human again after having been doped for twenty years. It was really an amazing experience.

The outcome for one of these patients gives insights into rehabilitation processes and staffpatient dynamics:

Dorothea had been on the ward for thirty years and she'd been cleaning the ward for thirty years, but she had been put on reserpine and she'd responded to it. I think she had been diagnosed originally as schizophrenic and she was really very well, and would we take her on [to clean our house]? ... I just gave her the keys ... and she went and cleaned my house ... And eventually she decided that she was well enough to leave the hospital and she got a job as a housekeeper for a local family who knew she was from Napsbury, so therefore they paid her hardly anything. And then she was successful at that job, so she got a better job and she used to come and visit ... bringing little presents for the children, she became a friend of the family.

The MHA, social expectations and policy ideas, along with new medications and a greater emphasis on rehabilitation, facilitated a move towards community care. The MHA allowed, but did not mandate, community care, with the result that local authorities were reluctant to fund it. Many hospitals built links with their local communities, but this was far from uniform, even between neighbouring hospitals (SC,21). It was dependent on the priorities of the local psychiatric leadership and staff creativity to nurture the links, ${ }^{22}$ for instance by encouraging local people to volunteer to support patients with activities, such as knitting: 'Simple things but bringing people together to do things that they never did before' (DJ,13). At Herdmanflat Hospital, 'the Round Table, the young version of Rotary ... became very interested in the hospital, ran events, and visited' (BB,52). DJ (12) accompanied Dr Russell Barton to schools and colleges where 'Russell would be preaching the gospel and encouraging people not to be frightened of this place on the edge of the town'. From some hospitals, staff began to visit discharged patients at home and 'this . . blossomed into a full community nursing service' alongside improved liaison with local social services (JB,51). BB (52) described how bringing people together was 'quite a therapeutic thing', improving links with local clergy and with family doctors who had 'been a bit distant from the hospital'.

\section{Evidence-Based Practice}

Notions of clinical scientific evidence in the 1960s contrasted with those used today: PT (34) commented: 'When someone very important made a statement or made an observation about a clinical problem, that was evidence ... I suppose it was the only evidence we had to go on.' Seminar participants recalled working with, or being taught by, 'very important' charismatic people, such as William Sargant (1907-88), R. D. Laing (1927-89) and Russell Barton (1923-2002). Each had firmly held views. Sargant advocated biological treatments, including prolonged sleep, insulin coma, ECT and high doses of medication, often in 
combination. Diametrically opposed, R. D. Laing promoted 'anti-psychiatry' concepts with entirely psychosocial models of, and treatment for, mental illnesses such as schizophrenia. Barton was vociferous that psychiatric hospitals must provide humane, dignified and rehabilitative treatment, but in the 1960s his methods were considered almost as radical as those of Sargant and Laing. All three stood on the fringes of conventional psychiatry, generated enthusiasm and hostility and provoked public and professional debate. Their styles of communication were as contentious as their clinical methods: both could impact on patients and colleagues, with constructive and destructive outcomes.

Barton's humanity enthused DJ (12) and helped shape his life work. Like the nurses, junior doctors could be inspired to follow in the footsteps of their seniors or, if disturbed by their experiences, could become determined to do things better. PT (31) recalled:

No one said anything about ethics. I first got my interest in randomised controlled trials by working for William Sargant ... I learnt more from him by what he did to excess than from others who taught me more correctly... But ... it really concerned me ... was I complicit in this in my very first psychiatric post ... ? The patient that got the insulin coma did get remarkably better (in the short term at least) and his parents were so pleased they gave a cheque to William Sargant, who gave it to me and said: 'Go and buy a couple of books.' The first one I bought was Principles of Medical Statistics by Austin Bradford Hill. [Working in Sargant's department] made me realise that doing things without any proper evidence was shocking.

\section{Variable Standards}

Many factors helped shape psychiatric hospital standards during the 1960s. No participants referred to poor standards in Scottish psychiatric hospitals. Scotland had similar mental health legislation to England and Wales but different policies on hospital closure, and new treatments and ideologies of deinstitutionalisation transformed care within them. ${ }^{23} \mathrm{BB}$ (53) noted that local people staffed Herdmanflat and the Royal Edinburgh Hospital, in contrast to the situation described south of the border. Staffing by local people (whose family and friends may also have been patients) may have facilitated communication and understanding between patients, staff and community, contrasting with hospitals which employed many staff recruited from further afield, who may have faced cultural and language challenges and lacked local social networks (PN,26; JH,46).

In England and Wales, government plans to close the psychiatric hospitals discouraged interest and expenditure on them. ${ }^{24}$ The MHA abolished the supervisory body for the psychiatric hospitals, leaving them without external inspection or oversight for most of the decade, until a new inspectorate was established in $1969 .^{25}$ While historiographies about NHS psychiatric hospitals in the 1960s are overwhelmingly disparaging, oral history accounts suggest that standards were far from uniform. This is compatible with reports from independent inquiries into psychiatric hospital care which found 'wide contrasts' within hospitals, with grave concerns about some wards but not others. ${ }^{26}$ SC (20) worked concurrently in a psychiatric hospital and a district general hospital and found better communication, team working and attitudes of the public to the psychiatric service and of the service towards the patients in the general hospital. John Wing and George Brown identified many differences between the three psychiatric hospitals they studied between 1960 and $1968 .^{27}$ They also highlighted the importance of idealistic leadership to improve standards, concurring with views of witnesses that leadership and vision were vital, such as 
to help overcome the tendency of staff to resist changing established practices previously regarded as safe and appropriate (JJ,38; HZ,38).

\section{Conclusion}

The 1960s were a decade of radical societal change, ideological battles within mental health services and a complex psychiatric hospital narrative. ${ }^{28}$ New medication, the MHA, multidisciplinary teams and ideals of community care provided opportunities to improve the lives of patients but not all hospitals grasped the nettle of implementation. Some in positions of responsibility endorsed neglect and old-fashioned methods, while others inspired improvements in patient care above and beyond expectations.

With the nature of medical 'evidence' ill-defined, and ethical frameworks unclear, clinical creativity by individual charismatic leaders entailed risks, particularly if associated with dogmatic inflexibility. Our witnesses' impressions, particularly about the extremes, from harshness and tragedies to humanity, were formative in their careers and persisted lifelong. Encounters with inhumane and disrespectful care and lack of autonomy for patients were unnerving for witnesses in the 1960s and for our seminar audience. It did not require an 'expert' to recognise the essence of 'good' and 'bad'. New or junior staff seemed more able to appreciate extremes than those accustomed to the local routines. Deference to seniority and a defensive leadership failed to enable the lower ranks to offer constructive criticism. However, people and practices perceived as 'good' provided role models and standards to emulate, whereas 'bad' spurred on others to achieve more humane and evidence-based care and treatment later in their careers.

Some witness seminar participants linked past to present. Why are there still scandals of care? How do we respond to practices we regard as unethical or harmful? Materially and scientifically psychiatric care has improved, but to what extent do unconstructive underlying societal beliefs and expectations perpetuate? We can learn from the experiences of our forebears and use the themes raised in this seminar to help us reflect on our roles, obligations, practices and standards today.

\section{Key Summary Points}

- The witness seminar revealed perspectives on the past which are not readily available in written sources.

- The memory of a tragedy, such as the suicide of a patient, can haunt involved staff members lifelong.

- Individual senior staff were role models who had profound effects on the course of junior clinicians' future careers.

- Wide contrasts in clinical standards and practices existed within and between hospitals.

- Many aspects of psychiatric practice have improved since the 1960s but others have not. Supported employment has been lost in the era of community care, scandals of poor care recur and staff may still fear speaking up when they experience or witness substandard practices.

\section{Notes}

1. G. Cohen, What's Wrong with Hospitals? Harmondsworth: Penguin, 1964. 
2. For the 1960 figures, see E. Brooke, Factors affecting the demand for psychiatric beds. Lancet (1962) 2: 1211-13; for 1973, see Department of Health and Social Security (DHSS), The Facilities and Services of Psychiatric Hospitals in England and Wales 1973. London: HMSO, 1976, pp. 54-5.

3. British Library. Mental Health Testimony Archive, http://cadensa.bl.uk/uhtbin/cgisirsi/?ps=OlKuJBwhd1/ WORKS-FILE/0/49.

4. W. Sargant, The Unquiet Mind: The Autobiography of a Physician in Psychological Medicine. London: Heinemann, 1967; H. Rollin, Festina Lente: A Psychiatric Odyssey. London: BMJ, 1990.

5. T. Tansey, The History of Modern Biomedicine: What Is a Witness Seminar?, www.histmodbiomed.org/ar ticle/what-is-a-witness-seminar.html.

6. C. Hilton and T. Stephenson (eds.), Psychiatric Hospitals in the UK in the 1960s. London: Royal College of Psychiatrists, 2020, www.rcpsych.ac.uk/docs/default-source/about-us/library-archives/archives/witnessseminar-final-transcript-july-2020-small.pdf?sfvrsn=4bceec71_2.

7. E. Goffman, Asylums: Essays on the Social Situation of Mental Patients and Other Inmates. Harmondsworth: Penguin, 1980. The first edition was published in 1961.

8. R. Barton, Institutional Neurosis. Bristol: Wright, 1966, p. 25.

9. Royal College of Physicians (RCP), Women and Medicine: The Future (Summary). London: RCP, 2009, www .rcr.ac.uk/sites/default/files/RCP_Women_\%20in_\%20Medicine_\%20Report.pdf.

10. P. Nolan, The development of mental health nursing. In J. Carson, L. Fagin and S. Ritter, eds. Stress and Coping in Mental Health Nursing, 1-18. London: Chapman and Hall, 1995; B. Robb, Sans Everything: A Case to Answer. London: Nelson, 1967.

11. Barton, Institutional Neurosis.

12. R. Sneddon, Psychiatric geriatric assessment unit at Crichton Royal Hospital, Nursing Mirror (1967): X-xv.

13. Ministry of Health, Methods of Dealing with Complaints of Patients, HM (66)15. London: HMSO, 1966.

14. C. Hilton, A tale of two inquiries: Sans Everything and Ely. Political Quarterly (2019) 90: 185-93.

15. DHSS, Report of the Committee of Inquiry into Allegations of Ill-Treatment of Patients and Other Irregularities at the Ely Hospital, Cardiff, Cmnd. 3975. London: HMSO, 1969, pp. 115-16.

16. E.g. A. Scull. Decarceration: Community Treatment and the Deviant - a Radical View. Cambridge: Polity Press, 1984.

17. SANE, Schizophrenia and Employment: Putting the Lived-Experience of Schizophrenia at the Heart of the Employment Agenda. 2013, www.sane.org.uk/uploads/schizophrenia_employment_web.pdf (accessed 18 July 2020).

18. DHSS, Report of the Committee of Inquiry into Allegations of Ill-Treatment of Patients, p. 80.

19. Ibid., pp. 78-80, 123.

20. British Psychological Society (BPS), Psychology Special Interest Group in the Elderly (PSIGE) Newsletter 1981/82 (Typescript, BPS archives).

21. E. Shorter, A History of Psychiatry: From the Era of the Asylum to the Age of Prozac. New York: John Wiley, 1997, pp. 239-67.

22. DHSS, Report of the Committee of Inquiry into Allegations of Ill-Treatment of Patients, p. 115.

23. V. Long, 'Heading up a blind alley'? Scottish psychiatric hospitals in the era of deinstitutionalization. History of Psychiatry (2017) 28: 115-28.

24. E. Powell, Opening speech. In Emerging Patterns for the Mental Health Services and the Public: Proceedings of a Conference at Church House Westminster, London on 9th and 10th March 1961, 5-10. London: National Association for Mental Health, 1961. This speech was subsequently dubbed the 'Water Tower' speech. See also Ministry of Health, A Hospital Plan for England and Wales, Cmnd. 1604. London: HMSO, 1962.

25. A. Baker, Hospital Advisory Service. BMJ (1972) 15: 176-7. 
26. DHSS, Report of the Committee of Inquiry into Whittingham Hospital. Cmnd. 4861. London: HMSO, 1972, p. 40.

27. J. Wing and G. Brown, Institutionalisation and Schizophrenia: A Comparative Study of Three Mental Hospitals 1960-1968. Cambridge: Cambridge University Press, 1970.

28. J. Turner, R. Hayward, K. Angel et al. The history of mental health services in modern England: Practitioner memories and the direction of future research. Medical History (2015) 59: 599-624. 